Vol. 2, No. 1, Juni 2021

\title{
SPEKTA
}

Jurnal Pengabdian Kepada Masyarakat : Teknologi dan Aplikasi

Journal homepage :

http://journal2.uad.ac.id/index.php/spekta

\section{STRATEGI NEGOSIASI DAN KONSEP KONTRAK PEMASARAN PADA KELOMPOK USAHA TEMPE DI MEDOKAN SEMAMPIR KOTA SURABAYA}

\section{Vieta Imelda $\mathbf{C}^{1}$, Dian Ferriswara ${ }^{2^{*}}$, Agustiawan Djoko $\mathbf{B}^{3}$}

Program Studi Ilmu Hukum, Universitas Dr. Soetomo Surabaya, Surabaya, Jawa Timur, Indonesia

Program Studi Ilmu Administrasi Niaga, Universitas Dr. Soetomo Surabaya, Surabaya, Jawa Timur, Indonesia Program Studi Manajemen, Universitas Dr. Soetomo Surabaya, Surabaya, Jawa Timur, Indonesia

\section{ARTICLE INFO \\ Received : November, 2020 \\ Revised : December, 2020 \\ Accepted : February, 2021}

Keywords:

tempe business;

letter of agreement;

digital marketing.

\begin{abstract}
Medokan Semampir Surabaya has a tempe business group chaired by Mrs. Pujianti, where when she founded her business for the first time, the tempe industry was one of the household agro-industries with great potential to be developed. Constraints on agreements between entrepreneurs and buyers who are large entrepreneurs whose credit payment patterns make entrepreneurs afraid of not being paid, so there is a need for an appropriate agreement for the security of both parties, with assistance in writing letters by legal practitioners and law teachers to make the agreement safe. Promotional assistance in the form of digital marketing also makes sales increase to buyers outside of existing ones. The purpose of this community service is to make micro entrepreneurs understand and be familiar with the safe sale and purchase legal agreements for sellers and buyers and to start entering the virtual world for selling their tempe products. This community service methodology is by direct assistance to entrepreneurs to make sales agreements and create social media accounts for digital marketing. The results of this community service are in the form of a letter of agreement and a social media account for tempe entrepreneurs
\end{abstract}

\section{PENDAHULUAN}

Kebutuhan gizi manusia yang semakin meningkat dan juga tingkat persaingan khususnya di bidang perdagangan yang semakin ketat maka dari itu kami memiliki ide gagasan untuk membuat suatu usaha kecil yang berupa makanan dengan yaitu tempe dan keripik tempe yang nantinya disukai dan mendapat respon positif dari para konsumen. Tempe, memang menjadi salah satu bahan makanan yang disukai dan diidolakan di Indonesia, baik di segala kalangan usia, mulai dari anak-anak hingga orang tua (Aryanta, 2020), ditambah, mulai muncul banyak sekali varian tempe yang tidak hanya digoreng

\footnotetext{
* Corresponding author.

E-mail address: dianferriswara@unitomo.ac.id

https://doi.org/10.12928/J.spekta.v2i1.3078
} 
Vol. 2, No. 1, Juni 2021

atau dijadikan campuran sayur, muncul cara pengolahan baru seperti steak tempe, yang merupakan metode diversifikasi pengolahan tempe dengan tujuan meningkatkan nilai jual dan memperluas spektrum pasar dari tempe itu sendiri (Raswanti et al, 2020). Medokan Semampir Surabaya mempunyai kelompok usaha tempe yang diketuai oleh Ibu Pujianti, dimana pada saat mendirikan usahanya pertama kali dimana industri tempe merupakan salah satu agroindustri rumah tangga yang sangat potensial untuk dikembangkan. Hal ini dikarenakan industri tempe telah mampu menciptakan lapangan kerja, meningkatkan pendapatan, dan meningkatkan perekonomian masyarakat pedesaan. Di tengah persaingan dengan industri rumah tangga lain baik yang dalam bidang pangan maupun non pangan serta iklim usaha yang semakin sulit menuntut industri tempe untuk lebih kreatif dalam menjalankan usaha. Agar dapat bertahan dan berkembang industri tempe perlu mengetahui faktor kunci sukses dalam berwirausaha tempe. Pengetahuan faktor kunci sukses berwirausaha tempe akan membantu para pengrajin tempe dalam menjalankan usaha. Selain itu juga akan membantu pihak-pihak yang terkait dalam pembinaan untuk membina para pengrajin tempe secara efektif dan efisien. Industri tempe merupakan industri kecil yang mampu menyerap sejumlah besar tenaga kerja baik yang terkait langsung dalam proses produksi maupun yang terkait dengan perdagangan bahan yang merupakan masukan maupun produk hasil olahannya.

Permasalahan yang timbul dalam pengembangan industri kecil dan rumah tangga (khususnya agroindustri) adalah tidak ditepatinya pembayaran oleh pihak pembeli kepada pihak pengusaha tempe, sehingga perlu adanya pembinaan secara intensif sekaligus pendampingan untuk membuat perjanjian usaha antara penjual dan pihak pengusaha tempe tentunya diawali dengan negosiasi dalam berkontrak. Permasalahan hasil identifikasi masalah ditemukan masalah utama yang dihadapi mitra, yaitu (1) belum mengerti dan pahamnya bagaimana perjanjian dagang yang harus dilakukan oleh pengusaha tempe dengan pihak ke 2 dan (2) belum melakukan pemasaran tempe secara baik dan profesional melalui media sosial juga.

Secara umum, pembahasan terkait penguatan UMKM pada level dan tataran akademis, masih sangat sedikit dilakukan, hal ini merupakan bukti bahwa masih sangat mungkin dan besar potensi terkait pembahasan pada UMKM, lebih jauh, profesionalisme dalam UMKM juga masih sangat jarang dilakukan dan dikerjakan terutama yang berkaitan dengan industri tempe dan berada di Surabaya. Budiyanto (2020), melakukan penguatan UMKM namun lebih menitikberatkan pada target ibu rumah tangga, dan berfokus pada usaha kecil menengah yang berada di Bali, penelitian ini lebih menitikberatkan pada peran ibu ibu Aisyiah, agar lebih memiliki kemampuan. Budiarti et al (2020), pada penelitiannya, memang membahas terkait pemanfaatan tepung labu kuning, obyek pada pelaksanaan penelitian ini memang pada produk konsumsi, dan bukan pada pengembangan UMKM terkait, melainkan pada pemanfaatan bahan sisa untuk meningkatkan daya jual masyarakat. Penguatan pengelolaan UMKM memang telah dilakukan oleh Hidayat et al (2020), terkait perbaikan proses organisasi hingga tata kelola, namun pada penelitian tersebut, obyek UMKM yang diteliti bukan merupakan produk ataupun obyek barang consumable, melainkan pada produk craft atau hiasan, berupa kain songket. Dari pemaparan penelitian-penelitian terdahulu, maka dapat ditarik sebuah hipotesis, bahwa pelaksanaan penguatan UMKM, memang telah dan pernah dilakukan, namun belum pernah dilakukan secara eksplisit kepada UMKM dengan jenis bisnis tempe, sehingga proses pelaksanaan program penguatan UMKM pada bisnis tempe ini masih sangat layak untuk dilakukan. 
Vol. 2, No. 1, Juni 2021

\section{METODE PELAKSANAAN}

Permasalahan yang ada pada mitra usaha tempe di Kelurahan Medokan Semampir Kecamatan Sukolilo Kota Surabaya yaitu pada bidang hukum khususnya negosiasi dan kontrak dan bidang pemasaran melalui online marketing. Sebelum kontrak terjadi maka pada tahap awal para pihak melakukan negosiasi mengenai apa yang akan disepakati, mulai dari identitas para pihak, pokok perjanjiannya, hak dan kewajiban masing-masing pihak, sanksi bagi pihak yang wanprestasi, berakhirnya perjanjian, domisili hukum terhadap penyelesaian sengketa. Untuk itu, beberapa asumsi yang harus dipegang dalam perancangan kontrak antara lain adalah:

1. Para pihak menandatangani kontrak karena memang benar-benar ingin melakukannya dan bukan ingin berperkara di pengadilan.

2. Kontrak yang dibuat harus memuaskan para pihak dan para pihak akan melaksanakan kontrak itu.

Perlu dipertimbangkan kemungkinan adanya wanprestasi atau tidak dapat dilaksanakannya obyek kontrak. Apa yang harus dilakukan oleh pihak lain apabila salah satu pihak memang melakukan wanprestasi atau apa upaya yang ditempuh pihak yang menderita kerugian akibat tidak dapat dilaksanakannya obyek kontrak. Disamping itu dalam perjalanan transaksi mungkin saja terjadi perbedaan penafsiran akan isi kontrak. Hal tersebut akan menyebabkan konflik antara para pihak. Dalam merancang suatu kontrak yang dapat memuaskan para pihak perancang kontrak harus memahami maksud para pihak, oleh karena itu sebaiknya ia diikutkan dalam negosiasi sehingga dapat menuangkan sejelas mungkin dan sebanyak mungkin keinginan dan maksud dari para pihak, sehingga sebanyak mungkin dapat dihindari kesalahpahaman.Setelah negosiasi dilaksanakan maka dituangkan dalam perjanjian. Perjanjian menurut pasal 1313 KUHPerdata adalah suatu persetujuan/suatu perbuatan dimana satu orang lain atau lebih, adanya perjanjian maka secara perdata mempunyai ikatan antara para pihak. Menurut Subekti, jual beli adalah suatu perjanjian dengan mana pihak yang satu mengikatkan dirinya untuk menyerahkan hak milik atas suatu barang dan pihak lain untuk membayarkan harga yang dijanjikan. Adapun sahnya perjanjian harus mempunyai unsur pada pasal 1320 KUH Perdata, yaitu adanya kesepakatan mereka yang mengikatkan dirinya, kecakapan untuk membuat suatu perikatan, suatu pokok persoalan tertentu, suatu sebab yang tidak dilarang. Dan yang terutama perjanjian harus didasari dengan itikad baik seperti yang tertuang dalam Pasal 1338 KUH Perdata. Dalam pelaksanaan diberi pelatihan negosiasi dan cara atau bentuk perjanjian secara umum dan sederhana.

Selanjutnya permasalahan yang dihadapi mitra dan solusi yang disepakati secara bersama dalam tabel 1 .

Tabel 1. Permasalahan Yang Dihadapi Mitra Dan Solusi Yang Disepakati

\begin{tabular}{lllll}
\hline Bidang & No & Permasalahan & Solusi yang Disepakati \\
\hline Hukum & 1 & Memahami perjanjian dagang / & Memberikan \\
& & perjanjian bisnis yang dilakukan & pembelajaran / pelatihan \\
& dengan pihak ke 2 & dan pendampingan \\
& & dalam pembuatan \\
& & perjanjian dengan pihak \\
& & ke 2 dalam sebuah \\
& & kerjasama bisnis \\
\hline
\end{tabular}


SPEKTA

Jurnal Pengabdian Kepada Masyarakat : Teknologi dan Aplikasi

Vol. 2, No. 1, Juni 2021

\begin{tabular}{clll}
\hline Pemasaran 1 & $\begin{array}{l}\text { Kebutuhan akan pelatihan dan } \\
\text { pendampingan pemasaran produk } \\
\text { tempe }\end{array}$ & $\begin{array}{l}\text { Melakukan pelatihan } \\
\text { dan pendampingan } \\
\text { pembuatan pemasaran } \\
\text { secara digital marketing, }\end{array}$ \\
\hline $2 \quad \begin{array}{l}\text { Bagaimana membuat online marketing Pelatihan: } \\
\text { dalam memasarkan usaha tempe di }\end{array}$ & $\begin{array}{l}\text { Akun bisnis / Medsos } \\
\text { Kelurahan Medokan Semampir } \\
\text { Kecamatan Sukolilo Kota Surabaya }\end{array}$ & $\begin{array}{l}\text { Instagram } \\
\text { Facebook) }\end{array}$ \\
\end{tabular}

\section{HASIL DAN PEMBAHASAN}

Berdasarkan uraian dari permasalahan serta hasil diskusi dengan mitra, maka prioritas permasalah yang harus diselesaikan bersama mitra adalah penguatan manajemen pengelolaan pemasaran tempe dan produksi keripik tempe. Adapun dalam pengabdian masyarakat yang diterapkan di usaha tempe di Kelurahan Medokan Semampir Kecamatan Sukolilo Kota Surabaya ada beberapa target capaian dalam solusi permasalahan mitra yaitu dapat dilihat pada table 2 .

Tabel 2. Tahapan Pelaksanaan Pengabdian Pada Masyarakat

\begin{tabular}{|c|c|c|}
\hline No & Tahapan & Operasional \\
\hline 1 & $\begin{array}{l}\text { Pelatihan dan pendampingan } \\
\text { pembuatan } \\
\text { kerjasama berjanjian } \\
\text { pihak ke } 2\end{array}$ & $\begin{array}{l}\text { Memberikan materi dan pendampingan kepada } \\
\text { mitra tentang bagaimana membuat surat } \\
\text { perjanjian usaha dengan pihak pembeli. }\end{array}$ \\
\hline 2 & $\begin{array}{l}\text { Melakukan pelatihan } \\
\text { pembuatan digital marketing } \\
\text { untuk memasarkan tempe }\end{array}$ & $\begin{array}{l}\text { - Akun bisnis/medsos (Digital Marketing: } \\
\text { Instagram dan Facebook) }\end{array}$ \\
\hline
\end{tabular}

Keberlanjutan program di lokasi pengabdian pada masyarakat pada usaha tempe yang dilaksanakan adalah sebagai berikut:

1. Menjalankan Manajemen Usaha secara profesional

2. Pemeliharaan Edukasi Pemasaran dan Perjanjian Usaha

3. Menjalankan marketing online secara kesinambungan

4. Menggalakkan UKM untuk mendukung pemasaran tempe dan keripik tempe Tabel 3 merupakan evaluasi pelaksanaan program yang akan dilakukan pada usaha tempe dan keripik tempe. 
Vol. 2, No. 1, Juni 2021

Tabel 3. Evaluasi Pelaksanaan Program

\begin{tabular}{|c|c|c|c|}
\hline No & Sebelum Program & $\begin{array}{l}\text { Sesudah } \\
\text { Program }\end{array}$ & Nilai Tambah \\
\hline 1 & $\begin{array}{l}\text { Tidak adanya surat } \\
\text { perjanjian antara } \\
\text { pengusaha dan } \\
\text { pembeli }\end{array}$ & $\begin{array}{l}\text { Mengetahui cara } \\
\text { membuat surat } \\
\text { perjanjian } \\
\text { kerjasama }\end{array}$ & $\begin{array}{l}\text { Menjamin pembayaran dari } \\
\text { pihak pembeli tepat waktu dan } \\
\text { menghindari terjadinya } \\
\text { tunggakan bahkan tidak dibayar } \\
\text { oleh pihak pembeli dengan tepat } \\
\text { waktu }\end{array}$ \\
\hline 2 & $\begin{array}{l}\text { Tidak mempunyai } \\
\text { akun bisnis / } \\
\text { medsos }\end{array}$ & $\begin{array}{l}\text { Memahami } \\
\text { pentingnya media } \\
\text { pemasaran untuk } \\
\text { meningkatkan } \\
\text { penjualan }\end{array}$ & $\begin{array}{l}\text { Terbentuknya akun bisnis / } \\
\text { medsos: (Digital Marketing: } \\
\text { Instagram dan Facebook) }\end{array}$ \\
\hline
\end{tabular}

Jadwal kegiatan pengabdian masyarakat pada mitra dikarenakan masih dalam masa pandemi Covid-19 maka pelaksanaannya telah dilakukan memberikan materi Sosialisasi Perjanjian Jual Beli dengan cara daring melalui aplikasi Zoom. Adapun kegiatan dari Strategi Negosiasi dan Konsep Kontrak Pemasaran Pada Kelompok Usaha Tempe di Medokan Semampir Kota Surabaya yaitu dapat dilihat pada gambar 1 sampai gambar 4.

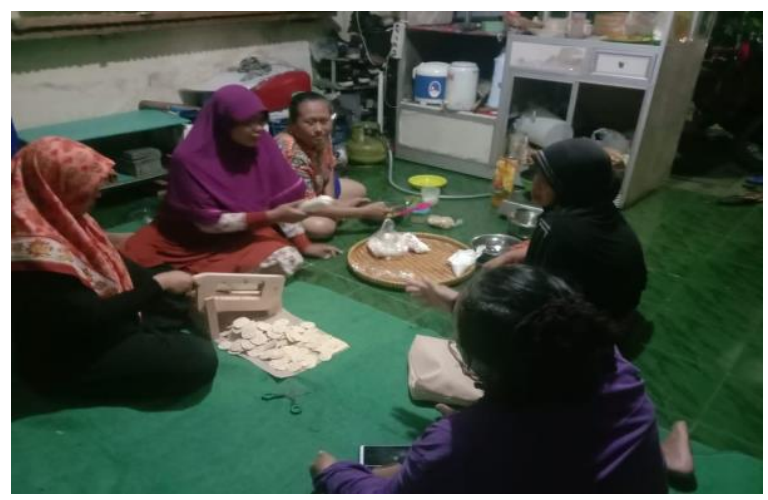

Gambar 1. Kegiatan oleh Kelompok Usaha Tempe Medokan Semampir

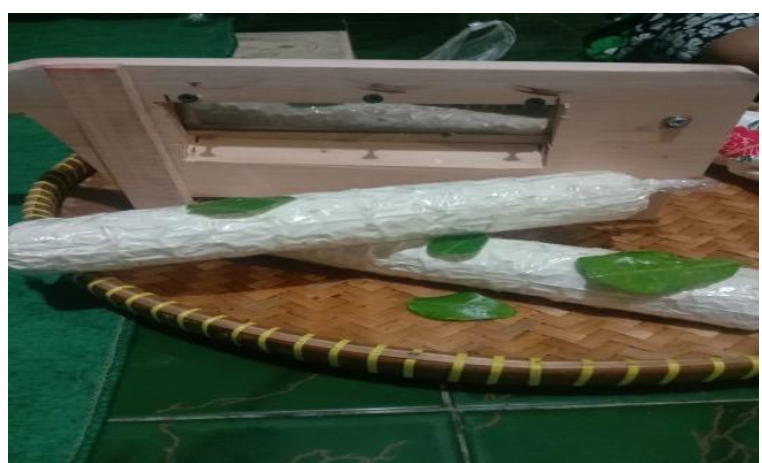

Gambar 2. Alat Pemotong Kripik Tempe yang Digunakan 
SPEKTA

Jurnal Pengabdian Kepada Masyarakat : Teknologi dan Aplikasi

Vol. 2, No. 1, Juni 2021

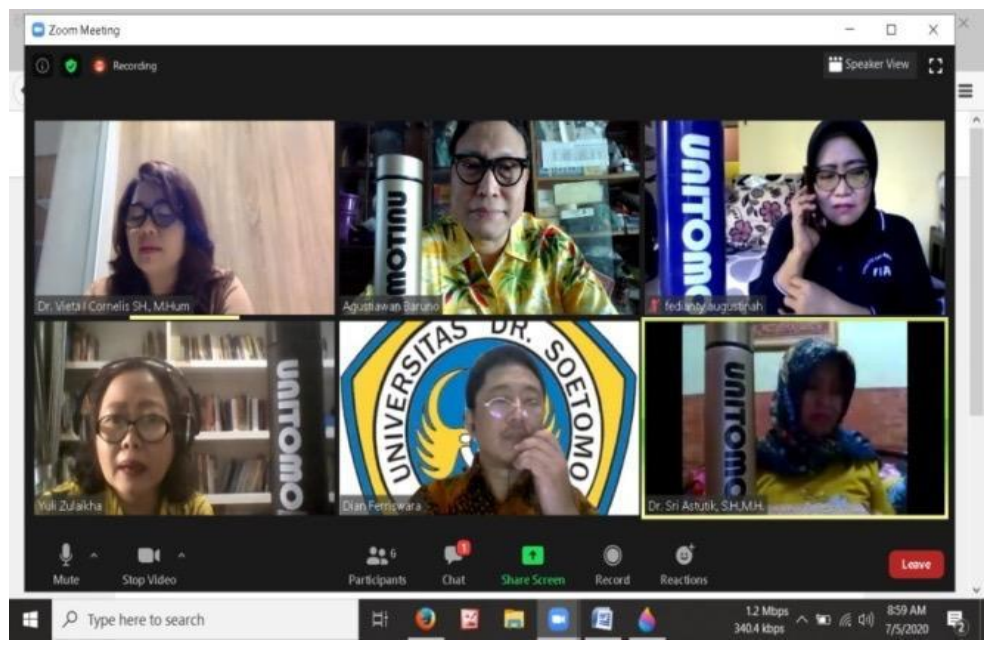

Gambar 3. Pemberian Materi Perjanjian Jual Beli dan Digital Marketing melalui apikasi Zoom

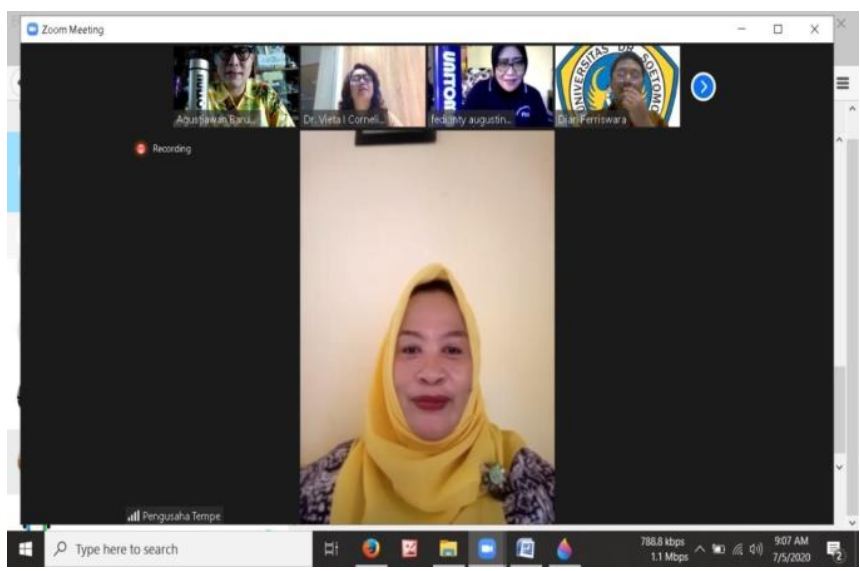

Gambar 4. Sosialisasi dan konsultasi Tim dengan Pujiati Ketua kelompok Usaha Tempe Medokan Semampir Surabaya melalui apikasi Zoom

Dalam pemberian materi tentang Negosiasi dan Konsep Kontrak Pemasaran Pada Kelompok Usaha Tempe Di Medokan Semampir Kota Surabaya ini diberitakan melalui berita online oleh media online. Beberita yang diterbitkan terkait pengabdian masyarakat ini dapat dilihat pada gambar 5 . 
SPEKTA

Jurnal Pengabdian Kepada Masyarakat : Teknologi dan Aplikasi

Vol. 2, No. 1, Juni 2021

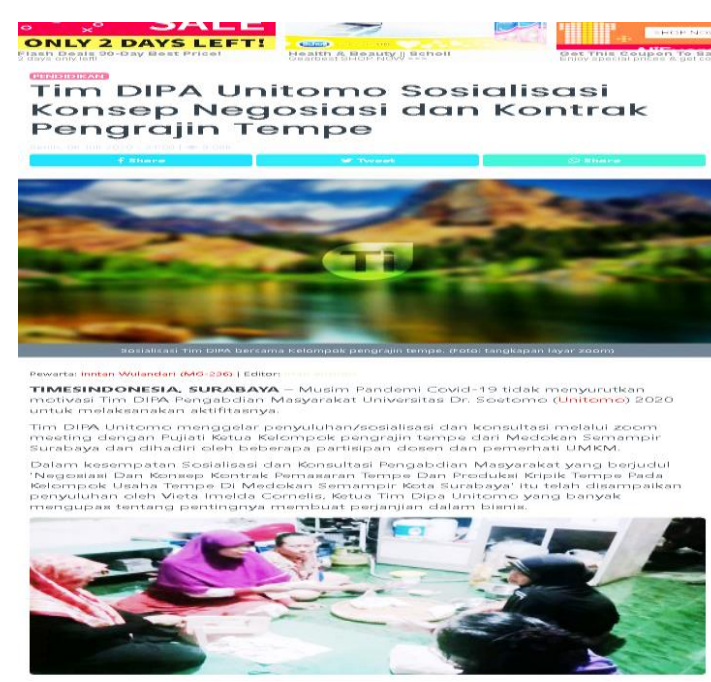

(a) TIMES Indonesia: Tim DIPA Unitomo Sosialisasi Konsep Negosiasi dan Kontrak Pengrajin Tempe

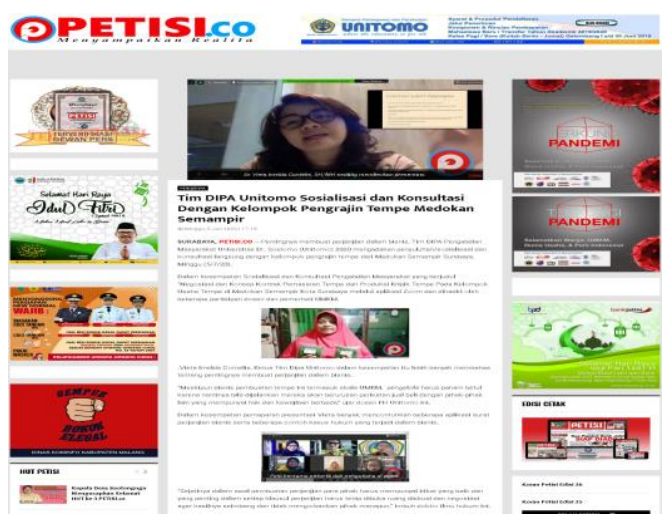

(c) Petisi.co
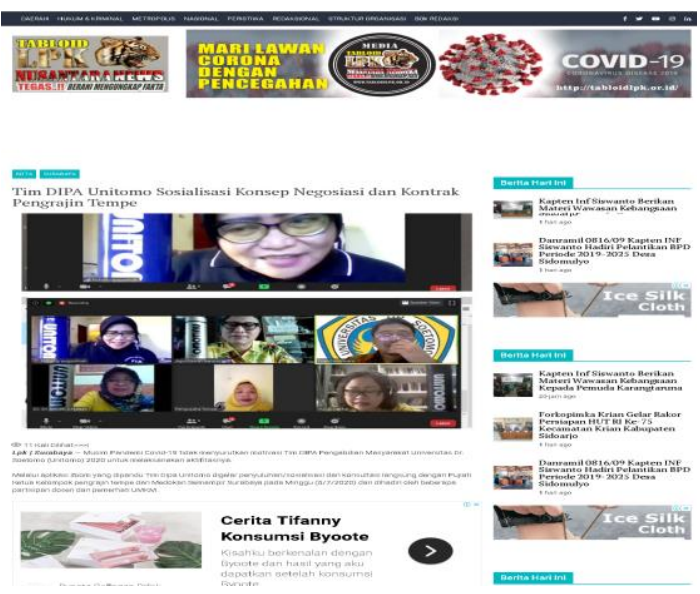

(e) Tabloid LPK

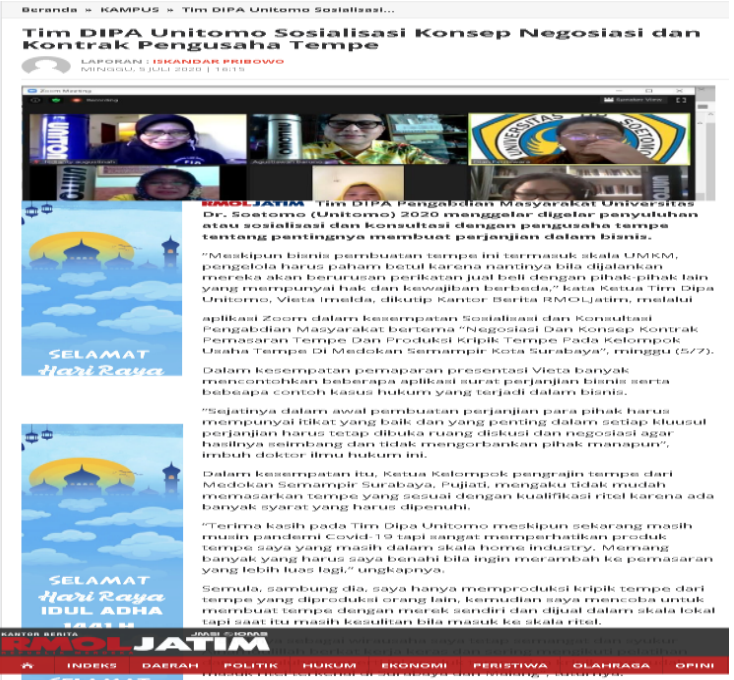

(b) MOL Jatim

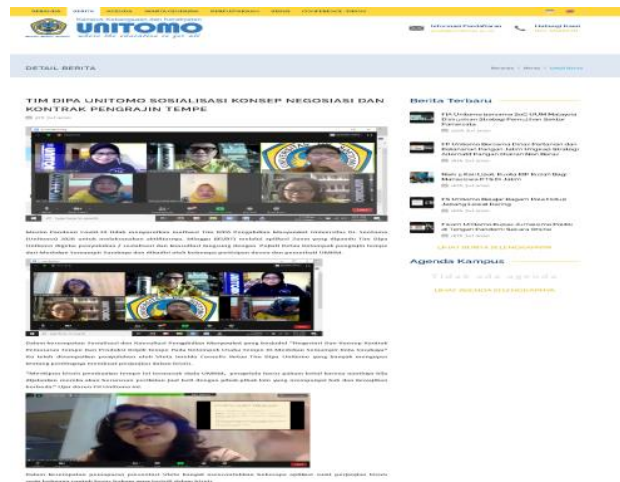

(d) Unitomo Web News

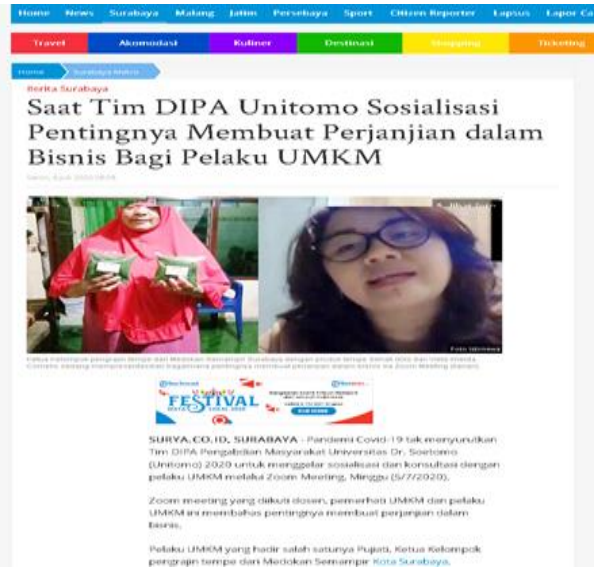

(f) Tribunnews

Gambar 5. Berita online terkait pengabdian masyarakat 
Vol. 2, No. 1, Juni 2021

\section{KESIMPULAN}

Semua kalangan masyarakat tentunya sudah mengenal dengan yang namanya tempe. Tempe merupakan bahan makanan yang dapat diolah untuk dijadikan sebuah masakan. Bisnis makanan yang menggunakan bahan baku tempe sangat banyak. Kebutuhan tempe setiap harinya semakin mengalami peningkatan. Pada pengabdian Masyarakat ini, team penulis melakukan pendampingan agar aspek hukum dari transaksi antara pengusaha dan pembeli dapat berkelanjutan dan aman dengan payung hukum perjanjian kedua belah pihak yang telah kami berikan pendampingan pembuatan perjanjiannya, juga pembuatan

Banyak masyarakat yang membutuhkan tempe sebagai bahan makanan yang diolah untuk setiap harinya. Melihat hal tersebut bagi kelompok usaha tempe dan keripik tempe Medokan Semampir yang bisa membuat tempe sebaiknya mencoba mengembangkan peluang bisnis tempe menjadi keripik tempe. Bisnis tempe memiliki potensi yang sangat menguntungkan. Menjalankan bisnis keripik tempe dapat dijalankan oleh semua kalangan masyarakat, hal ini yang mendasari kelompok usaha keripik tempe yang ada di Medokan Semampir selama ini untuk membuka usaha ini.

Saran yang dapat dipergunakan untuk perbaikan untuk pengusaha / kelompok usaha tempe di Medokan Semampir yaitu:

1. Peluang bisnis keripik tempe harus menyiapkan segala kebutuhan bahan yang diperlukan termasuk alat pemotong tempe yang memadai sesuai standar,

2. Kelompok Usaha Tempe dan Keripik Tempe Medokan Semampir yang ingin menjalankan bisnis keripik tempe juga perlu mengetahui hitungan analisa usahanya, sehingga kelompok usaha tempe dan keripik tempe ini membutuhkan pendampingan kembali.

3. Membuat Keripik Tempe dengan Berbagai Varian Rasa dan Kemasan yang Menarik untuk usaha tempe dan keripik tempe di Kelompok Usaha Tempe dan Keripik Tempe di Medokan Semampir Kota Surabaya

\section{DAFTAR PUSTAKA}

Aryanta, I. W. R. (2020). Manfaat tempe untuk kesehatan. Widya Kesehatan, 2(1), 4450.

Budiarti, G. I., Wulandari, A., \& Mutmaina, S. (2020). Pemanfaatan tepung labu kuning modifikasi hydrogen rich water kepada masyarakat. $S p, 1(1), 11-16$.

Budiyanto, T. (2020). Strategi pemasaran usaha kecil menengah pada ibu- ibu aisyiah muhammadiyah bali. SPEKTA Jurnal Pengabdian Kepada Masyarakat: Teknologi Dan Aplikasi, 1(1), 16-20.

Bungin, Burhan. 2015. Komunikasi Pariwisata Pemasaran Dan Brand Destinasi. Jakarta: Kencana

Hidayat, Gunadi, Arlangga, L., \& Yulianti, F. (2020). Pengelolaan Kain Tenun Songket Khas Palembang di desa Pedu Kabupaten Jejawi Kecamatan Ogan Komering Ilir (OKI). SPEKTA Jurnal Pengabdian Kepada Masyarakat: Teknologi Dan Aplikasi, 1(1), 21-30.

Kevin, Lane Keller. 1998. Strategic Brand Management: Building, Measuring, and Managing Brand Equity. NJ: Prentice Hall 
Vol. 2, No. 1, Juni 2021

Kurnadi, M. 2015. Penggunaan Internet of Thing (IoT) untuk Pengembangan Smart City di Indonesia [Online] Available at: https://id.techinasia.com/penggu naan-iot-untukpengembangansmart-city-di-indonesia

Kitab Undang Undang KUHPerdata.

Raswanti, H., Aditya, A. O., Aisyah, S. R. O., Alham, A., \& Hanidah, I.-I. (2018). UPAYA PENINGKATAN KONSUMSI TEMPE MELALUI DIVERSIFIKASI OLAHAN. Agricore, 3(1), 401-406.

Subekti R, 1987, Hukum Perjanjian, Bina Cipta, Bandung

Website Muchamad, Bani Noor. (2015). Konsep Ekspresi Kota Sebagai Pendekatan Membangun Atau Memperkuat Citra Kota)

https://radarsurabaya.jawapos.com/read/2019/08/14/150923/tim-ssc-dorong-potensidan-semangati-warga-medokan

https://pakarkomunikasi.com/pemanfaatan-media-sosial-untuk-promosi-wisata 
SPEKTA

Jurnal Pengabdian Kepada Masyarakat : Teknologi dan Aplikasi

Vol. 2, No. 1, Juni 2021

Halaman ini sengaja dikosongkan

This page is intentionally left blank. 